\title{
Development Status and Global Competition Trends Analysis of Maglev Transportation Technology Based on Patent Data
}

\author{
Jinsong Gou ${ }^{1}$ D
}

Received: 21 July 2018/Revised: 28 July 2018/Accepted: 10 August 2018/Published online: 20 August 2018

(C) The Author(s) 2018

\begin{abstract}
This study investigates magnetic levitation (maglev) transportation technology's development status and global competition trends by mining patent data related to maglev transportation technology from five perspectives. It uses information collected from the Innography patent database: the number of annually registered patents throughout maglev's development history, the key patentcontributing countries and their global distribution, the top 20 innovative organizations in maglev transportation technology, their organization type, and the technology distribution classifications of their patents, core patents, and their holders and registered regions. A comparison and analysis are carried out based on patent data. The study summarizes the development and main trends of maglev technology, the countries with strong competition, the markets with the most potential for maglev technology application, the focuses of technological research and development, and the future research directions of major innovative organizations and their core patents. The study offers suggestions and recommendations from both national/governmental (macro) and organizational (micro) perspectives.
\end{abstract}

Keywords Maglev transportation - Data mining - Global patent distribution - Core patent - Competitive situation . Innovative organization

Jinsong Gou

jinsonggou@aliyun.com

1 Beijing Rail Transit Technology and Equipment Group Co., Ltd, Beijing 100027, Sichuan Province, China

Communicated by Baoming Han.

\section{Introduction}

The magnetic levitation (maglev) transportation system is a rail transport method that uses electromagnetic forces generated by a linear motor system to repel and push a train along its track (levitation) as well as to move the train toward its destination. Maglev transportation systems have many advantages over traditional urban rail transit systems such as subways, light rail, monorail, and trams, such as greater safety, stronger environmental adaptability, stronger climbing performance, lower performance-cost ratios, less noise, and lower radiation. Therefore, maglev technology is considered an "eco-friendly" method of travel in the twenty-first century.

Several maglev transportation systems have been constructed and put into operation around the world, such as the Shanghai high-speed Maglev Transit line in China (also known as Transrapid) that runs from Shanghai Pudong International Airport to Longyang station, which is an interchange station, and connects to Shanghai subway line $2[1,2]$. The other lines are operated at low-to-medium speeds, such as Linimo in Aichi Prefecture, Japan [3, 4], the low-to-medium speed Incheon Airport Maglev that runs from Incheon Airport in South Korea [5], the low-speed Changsha Maglev Line that runs from Changsha Huanghua International Airport in China [6], and the low-speed Beijing S1 maglev transportation line in China [7]. Based on strong market potential, maglev transportation systems have gradually become integrated into urban rail transit systems. The successful construction and operation of maglev transportation lines show that maglev transportation is a promising public transportation system that will play an important role in the future of transport systems [8]. 
Maglev technology is a potential solution for future traffic and ecological challenges because the main advantages of maglev technology are obvious: short trip times due to its high speed and/or high acceleration; a high level of safety and comfort due to its magnetic guidance and levitation systems; low operating costs due to the low maintenance effort required (as it is contactless) and high efficiency; flexible alignment due to the high gradients because there is no need for a functional grip between the wheel and the rail; and its eco-friendliness due to its highefficiency, emission-free system, flexible alignment, low noise, and independence from energy modes [9]. Maglev developers claim that their system can achieve higher speeds and lower energy consumption and life-cycle costs and can take more passengers, while producing less noise and vibration than high-speed rail [10]. Therefore, Maglev transportation has the potential to be more efficient and affordable than alternative technologies for many transportation applications [11].

The research on and application of maglev transportation technology are abundant. Chan and Aldhaban introduce and compare the major determinants of international technology transfer strategies in the high-speed rail industry from the perspectives of both technology import and export [12]. Minakami introduces a new paradigm of the road by using maglev vehicles [13]. Barber discusses the market for maglev technology for urban applications [14]. Hellinger and Mnich compare the different types of linear motors in maglev transportation [9]. Thornton outlines the keys to reducing energy intensity by using light vehicles with low aerodynamic drag. The key to affordability is to use small, light vehicles that can operate on less-expensive guideways and that require less power for propulsion [11]. The academic and engineering research on maglev technologies lends strong support to the benefits of maglev technology's commercial application. Maglev can be both less expensive and more efficient than its alternatives. Maglev has the ability to achieve much higher acceleration and braking rates than steel wheels on steel rails. Designs that take advantage of this fact will maximize efficiency and cost-effectiveness. Maglev's greatly reduced noise, improved ride quality, and reduced energy consumption will make it much easier to sell high-speed ground transportation [11].

This study explores the current maglev transportation development situation and technology trends by mining maglev transportation patent data from a commercial patent database, analyzing the data, and summarizing the maglev transportation development situation and technology trends. Patent data reflect the latest cutting-edge scientific and technological intelligence. Therefore, analyzing patent data may provide useful indicators for the development of corresponding technologies in a nation, region, and industry, as well as the distribution and development trends of the technologies across nations, regions, and industries. The results of this analysis may help governments and enterprises concentrate essential resources on key technologies, thereby achieving swifter technological catch-up and leapfrog development in the industry.

Based on patent data related to maglev technology from the Innography patent database, the developmental stages and trends of global maglev technologies are analyzed. The main contributing countries with patents, the global distribution of key patents, the focus of the associated technological research and development, the most innovative organizations, and the most valuable patents are also analyzed. The purpose of this research is to provide references that governmental decision-makers can use when formulating supporting policies as well as to help enterprises establish strategies for technological research and development and make appropriate market decisions as maglev transportation systems continue to develop.

\section{Maglev Patent Data Sources and Search Results}

The data used in this study were obtained from the Innography patent database. Innography is a web-based platform developed by ProQuest Dialog, a member of Cambridge Information Group, that provides online applications and tools related to intellectual property business intelligence. The database has grown to incorporate patent search and analysis tools that enable the mining of core patents and patent quality assessment [15]. The Innography platform includes the patent families, legal statuses, and original descriptions of patents from more than 90 countries and regions, covering approximately 40 years and 60,000 patent litigation entries from the Public Access to Court Electronic Records (PACER) provided by the Federal Judiciary of the USA, as well as financial data on the patentees released by Dun and Bradstreet and the US Securities and Exchange Commission [16].

Based on English terms relevant to the subject of maglev transportation systems and international patent classification codes, the following search parameters were used for the research data queries: @ (abstract, claims, title) [(electromagnetic* or magnetic*) and (levitat* or suspen*) or maglev or EML] and (rail* or trans* or train* or vehicle) @* and (ipc_B60 or ipc_E01 or ipc_B61). The search was conducted on November 26, 2017, yielding 12,269 corresponding patents. Patents with classification codes B000 (Performing Operations), E000 (Fixed Constructions), H000 (Electricity), F000 (Mechanical Engineering), G000 (Physics), and A000 (Human Necessities) accounted for $76.68,12.46,4.85,2.68,1.8$, and $0.29 \%$ of the total, 
respectively. The remaining $1.24 \%$ of the patents belonged to other categories.

\section{Analysis of Maglev Patent Data Search Results}

\subsection{Analysis of Global Development Stages and Trends in Maglev Technology}

Changes in the number of annual patent applications may provide an overview of the development trends in a given technological field. Maglev-related patent applications from 1998 to 2016 are shown in Fig. 1 based on the patent's priority year. The figure shows that, in general, applications of maglev-related patents have been growing. Based on the number of proposals involving maglev technology and the corresponding scientific discoveries, we extended the timeline to include a review of the development history of and trends in the maglev transportation system. We divided the development of maglev technology into three stages $[17,18]$.

The first stage is denoted the "stage of scientific discovery (1842-1934)." The concept of magnetic levitation was first proposed by British physicist Samuel Earnshaw in 1842. In 1922, German engineer Hermann Kemper proposed the principle of electromagnetic levitation. He was awarded the world's first patent for maglev technology in August 1934 (Reichs Patent number 643,316). During this first stage, patented maglev technology was developed from scratch, and the development of the technology was slow.

The second stage is denoted the "stage of technological invention (1934-2003)." Starting from the validation of laboratory models, Germany developed eight generations of maglev trains (TR01 to TR08). Japan achieved results from the research and development of conventional maglev trains through the application of superconducting magnets.
Beijing Enterprises Holdings Maglev Technology Development Co. Ltd. (Beijing Maglev) cooperated with the National University of Defense Technology in the development of sample maglev trains, built the first domestically developed maglev line, and put it into trial operation in Changsha, China. During this stage, the number of maglevrelated patent applications grew rapidly. In 2003, the world's first commercial high-speed maglev was put into operation in Shanghai, marking the transformation of maglev technology from laboratory samples to valuable prototype products. As a result, applications for maglevrelated patents peaked in 2004, at 553 .

The third stage is denoted the "stage of engineerization of the technology (2003-2017)." The low-to-medium speed maglev lines in the Aichi Prefecture in Japan and the Incheon Airport in South Korea were successively put into operation. The test of the TR09 was completed in Germany, and the Chinese Ministry of Science and Technology listed maglev technology as one of the major research projects of the 863 Program (also known as State HighTech Development Plan). In 2011, the Beijing Maglev S1 line, the first developed maglev line in China, began its construction. Applications of maglev-related patents continued to grow in the successive years. In 2016, the number of patent applications reached a total of 721 , with a growth rate of $14 \%$. In the same year, the low-to-medium speed maglev train between Changsha Huanghua International Airport and Changsha South Railway Station in China began trial operations. In 2017, the Beijing S1 Line that connects Shimenying of the Mentougou District and Pingguoyuan of the Shijingshan District was put into commercial operation. This achievement symbolized the maturing of maglev technology, as its stability and advancement were deemed fit to serve the public. Thus, the development of maglev technology officially entered the stage of industrialization.

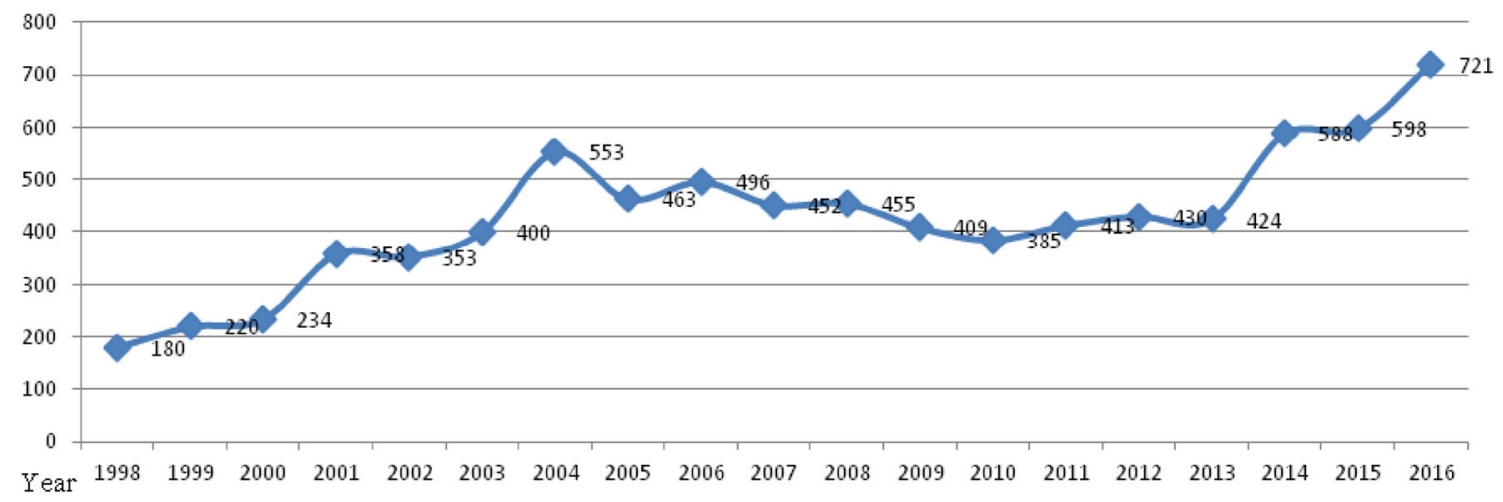

Fig. 1 Annual applications of maglev-related patents from 1998 to 2016. Data Source: Innography patent database (extracted on November 26, 2017) 


\subsection{Key Patent-Contributing Countries and Global Distribution of Patents}

\subsubsection{Key Patent-Contributing Countries}

Patent-contributing countries are the home countries of the patentees. The top 10 patent-contributing countries, sorted based on the number of patents, are shown in Fig. 2. As the figure shows, the five leading countries in maglev technology are China $(3360,27.11 \%)$, Japan $(3026,24.66 \%)$, Germany $(2508,20.44 \%)$, the USA $(1312,10.69 \%)$, and South Korea $(536,4.37 \%)$. The patent applications from these five countries total 10,714 account for $87.55 \%$ of global patent applications. This indicates that patent contributions in this field are highly concentrated and that the core technologies are largely controlled by the five countries listed above.

Although the development of maglev technology in China began relatively late (in the late 1990s), the number of patent applications increased from eight in 1998 to 663 in 2016, a growth of 82.88 times in less than 20 years. As a result, China has become a major contributor of maglevrelated patents. Clearly, China's technological innovation and independent research and development capacity have made rapid progress in recent years. Moreover, awareness of intellectual property and rights protection has grown among Chinese patentees.

\subsubsection{Analysis of Technology Growth in Patent- Contributing Countries}

A technology growth index can reflect the development of a given technology at different stages. The index is calculated by $V=a / A$, where $V$ represents the patent growth

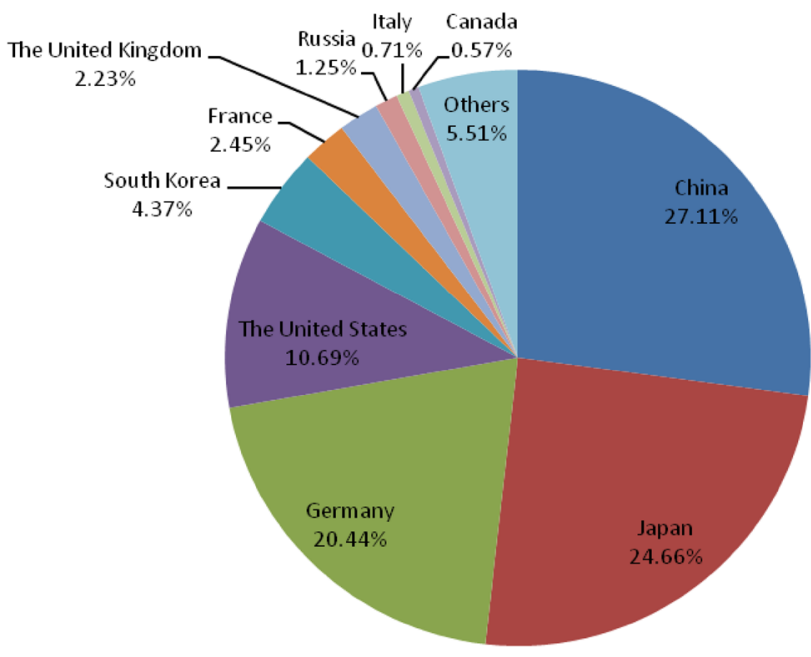

Fig. 2 Top 10 patent-contributing countries. Data Source: Innography patent database (extracted on November 26, 2017) rate of a given year, $a$ represents the number of patent applications in the given year, and $A$ represents the cumulative patent applications in the previous 5 years (excluding those in the given year). An increasing value of $V$ indicates that the corresponding technology of a given country or region is in its infancy or growth stage, whereas a decreasing value of $V$ indicates that the corresponding technology of a given country or region is already at a mature stage [19]. The technology growth index of the top five patent-contributing countries for 2003-2016 (see Fig. 3) shows that the overall development of maglev technology has entered a mature stage. Specifically, maglev technology in Germany, Japan, South Korea, and the USA has entered a mature stage, whereas maglev technology in China is still developing and maturing gradually.

\subsubsection{Global Distribution of Patents}

The global distribution of patents from contributing countries reflects the patentees' global strategy as well as the countries and regions where the corresponding patented technology may be implemented in the future. Table 1 presents the distribution of patents from the top five contributing countries, extending from the originating country outward to other countries. The $Z$-axis indicates the country of the patentees, the $X$-axis indicates the countries where the patented technology is registered, and the $Y$-axis indicates the number of patents.

Table 1 shows that Germany's patented maglev technologies have the most extensive distribution coverage (33 countries and regions). The number of patented technologies registered domestically in Germany account for $43.46 \%$ of all patented technologies; this is followed by the number of patented technologies registered in the USA (13.79\%), at the European Patent Organization (EPO) (11.12\%), and in China (10.65\%). The patented maglev technologies of the USA are registered in 26 countries and regions. The number of patented technologies registered domestically in the USA account for $44.67 \%$ of all patented technologies, followed by the patented technologies registered at the EPO (10.73\%), in Germany (10.19\%), and in China $(7.74 \%)$. The patented maglev technologies originating from Japan are registered in 17 regions. The number of patented technologies registered domestically in Japan account for $78.62 \%$ of all patented technologies, followed by the patented technologies registered in the USA, Germany, at the EPO, and in China, which account for $6.96,5.15,3.73$, and $2.54 \%$ of the total number of patented technologies, respectively. China's patented technologies are registered in 11 countries and regions. Most Chinese patented technologies are registered domestically $(97.17 \%)$, followed by patented technologies 
Fig. 3 Technology growth in the top five patent-contributing countries. Data Source: Innography patent database (extracted on November 26, 2017)

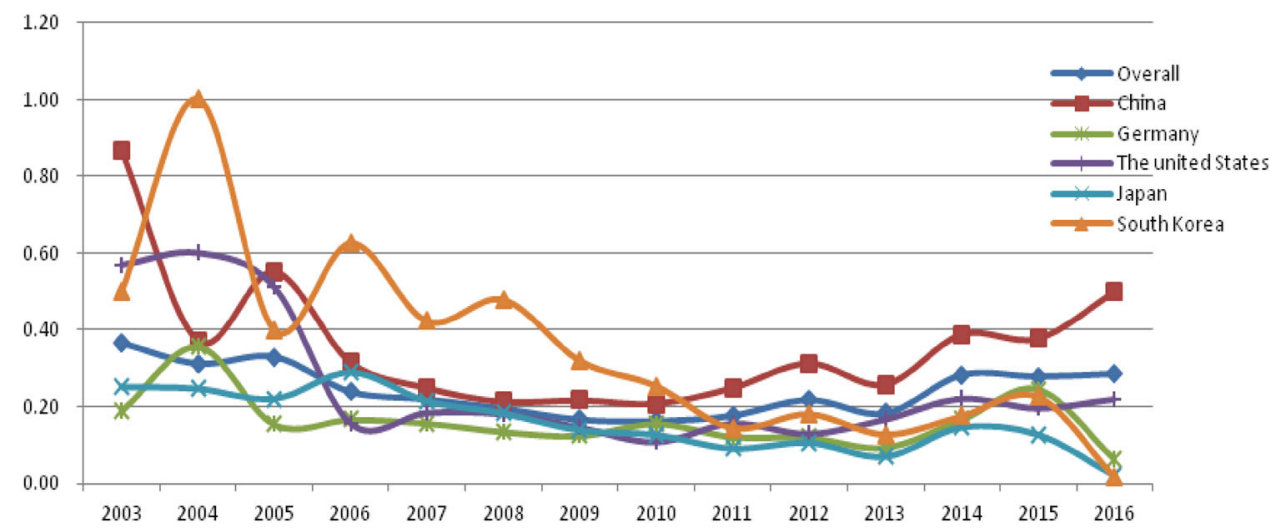

Table 1 Global distribution of patents from the top five patent-contributing countries. Data Source: Innography patent database (extracted on November 26, 2017)

\begin{tabular}{|c|c|c|c|c|c|}
\hline Patentee country where patents are registered & China & Germany & USA & Japan & South Korea \\
\hline China & $3232(97.17 \%)$ & $268(10.65 \%)$ & $101(7.74 \%)$ & $77(2.54 \%)$ & $20(3.74 \%)$ \\
\hline Germany & $16(0.48 \%)$ & $1094(43.46 \%)$ & $133(10.19 \%)$ & $156(5.15 \%)$ & $6(1.12 \%)$ \\
\hline USA & $31(0.93 \%)$ & $347(13.79 \%)$ & $583(44.67 \%)$ & $211(6.96 \%)$ & $20(3.74 \%)$ \\
\hline Japan & $3(0.09 \%)$ & $161(6.4 \%)$ & $96(7.36 \%)$ & $2383(78.62 \%)$ & $4(0.75 \%)$ \\
\hline South Korea & $5(0.15 \%)$ & $22(0.87 \%)$ & $23(1.76 \%)$ & $9(0.3 \%)$ & $472(88.22 \%)$ \\
\hline UK & $3(0.09 \%)$ & $212(8.42 \%)$ & $118(9.04 \%)$ & $87(2.87 \%)$ & \\
\hline France & $3(0.09 \%)$ & $161(6.4 \%)$ & $70(5.36 \%)$ & $68(2.24 \%)$ & \\
\hline Canada & & $74(2.94 \%)$ & $81(6.21 \%)$ & $23(0.76 \%)$ & \\
\hline Australia & & $42(1.67 \%)$ & $34(2.61 \%)$ & $17(0.56 \%)$ & \\
\hline Russia & & $18(0.72 \%)$ & $13(1 \%)$ & $5(0.16 \%)$ & $1(0.19 \%)$ \\
\hline Italy & $3(0.09 \%)$ & $110(4.37 \%)$ & $63(4.83 \%)$ & $27(0.89 \%)$ & $2(0.37 \%)$ \\
\hline Czech Republic & $3(0.09 \%)$ & $59(2.34 \%)$ & $35(2.68 \%)$ & $14(0.46 \%)$ & \\
\hline WIPO & $32(0.96 \%)$ & $123(4.89 \%)$ & $106(8.12 \%)$ & $24(0.79 \%)$ & $11(2.16 \%)$ \\
\hline EPO & $4(0.12 \%)$ & $280(11.12 \%)$ & $140(10.73 \%)$ & $113(3.73 \%)$ & $2(0.37 \%)$ \\
\hline
\end{tabular}

registered with the World Intellectual Property Organization (WIPO) $(0.96 \%)$, the USA $(0.93 \%)$, and Germany $(0.48 \%)$. South Korea's patented maglev technologies are registered in nine countries and regions; $88.22 \%$ of South Korea's patented technologies are registered domestically, and the patented technologies registered in the USA, China, and with the WIPO account for 3.74, 3.74, and $2.06 \%$ of all patented technologies, respectively. These data show that the major patent-contributing countries have focused on the domestic registration of patented technologies, and have then expanded their coverage based on local research and resource development.

\subsection{Distribution of Major Research Areas and Focuses}

The international patent classification (IPC) is the globally recognized patent classification system. Table 2 presents
IPC classification codes and descriptions of the patents related to maglev technology (Fig. 4).

Analyzing the classification of patent technologies can generate a distribution of patent classifications (see Fig. 5), which reflects the research focus in this field. Figure 5 shows that the research focus for maglev transportation is technologies related to electric propulsion for vehicles (B60L, 22.86\%) and vehicle suspension control (B60G, $18.46 \%$ ), followed by technologies related to railway systems and equipment $(\mathrm{B} 61 \mathrm{~B}, 7.07 \%)$ and railway construction (E01B, 8.23\%), passenger facilities (B60N, 1.5\%) and shock reduction and absorption $(\mathrm{F} 16 \mathrm{~F}, 1.34 \%)$, bogies (B61F, 1.07\%), and brake control systems (B60T, 1\%).

As shown in Table 3, the research focus of the five countries is essentially consistent with the global research focus (B60L, B60G, B61B, and E01B), which further confirms that these sub-classifications of technologies represent the main research focuses and target directions 
Table 2 Maglev technology-related IPC classification codes and descriptions

\begin{tabular}{|c|c|c|c|}
\hline $\begin{array}{l}\text { IPC } \\
\text { code }\end{array}$ & Description & $\begin{array}{l}\text { IPC } \\
\text { code }\end{array}$ & Description \\
\hline B000 & Performing operations & H000 & Electricity \\
\hline B60B & Increasing wheel adhesion & $\mathrm{H} 01 \mathrm{~F}$ & $\begin{array}{l}\text { Magnets; inductances; transformers; selection of materials for } \\
\text { their magnetic properties }\end{array}$ \\
\hline B60C & $\begin{array}{l}\text { Vehicle tires; tire inflation; tire changing; general connecting } \\
\text { valves to inflatable elastic bodies; devices or arrangements } \\
\text { related to tires }\end{array}$ & $\mathrm{H} 02 \mathrm{~J}$ & $\begin{array}{l}\text { Circuit arrangements or systems for supplying or distributing } \\
\text { electrical power; systems for storing electrical energy }\end{array}$ \\
\hline B60D & Vehicle connections & $\mathrm{H} 02 \mathrm{~K}$ & Dynamo-electric machines \\
\hline B60G & Vehicle suspension arrangements & $\mathrm{H} 02 \mathrm{~N}$ & Electric machines not otherwise provided for \\
\hline $\mathrm{B} 60 \mathrm{H}$ & Heating, cooling, ventilating devices & $\mathrm{H} 02 \mathrm{P}$ & $\begin{array}{l}\text { Control or regulation of electric motors, electric generators or } \\
\text { dynamo-electric converters }\end{array}$ \\
\hline B60J & Windows, windscreens, non-fixed roofs & F000 & Mechanical engineering \\
\hline B60K & Arrangement of propulsion units or transmissions in vehicles & F16F & Springs; shock-absorbers; means for damping vibration \\
\hline B60L & $\begin{array}{l}\text { Electric propulsion for monorail vehicles, suspension vehicles } \\
\text { or rack railways; magnetic suspension or levitation for } \\
\text { vehicles }\end{array}$ & $\mathrm{F} 16 \mathrm{H}$ & Gearing \\
\hline B60M & $\begin{array}{l}\text { Power supply lines, or devices along rails, for electrically } \\
\text { propelled vehicles }\end{array}$ & F16K & $\begin{array}{l}\text { Valves; taps; cocks; actuating-floats; devices for venting or } \\
\text { aerating }\end{array}$ \\
\hline B60N & Arrangements or adaptations of other passenger fittings & F16M & $\begin{array}{l}\text { Frames, casings, or beds, for engines or other machines or } \\
\text { apparatus }\end{array}$ \\
\hline B60P & $\begin{array}{l}\text { Vehicles adapted for load transportation; or to transport, carry, } \\
\text { or comprise special loads or objects }\end{array}$ & E000 & Fixed construction \\
\hline B60Q & $\begin{array}{l}\text { Arrangement of signaling or lighting devices, the mounting or } \\
\text { supports thereof, or circuits therefore, for vehicles in } \\
\text { general }\end{array}$ & E01B & $\begin{array}{l}\text { Permanent way; permanent-way tools; machines for making } \\
\text { railways of all kinds }\end{array}$ \\
\hline B60R & Vehicles, vehicle fittings, or vehicle parts & E01C & $\begin{array}{l}\text { Construction or surfacing of roads, sports grounds, or similar; } \\
\text { machines or auxiliary tools for construction or repair }\end{array}$ \\
\hline B60S & Servicing, maintaining, repairing, or refitting of vehicles & E01D & $\begin{array}{l}\text { Methods or apparatus specially adapted for erecting or } \\
\text { assembling bridges }\end{array}$ \\
\hline B60T & Vehicle brake control systems & E01F & Landing stages for helicopters \\
\hline B60W & $\begin{array}{l}\text { Conjoint control of vehicle sub-units of different types or } \\
\text { different functions }\end{array}$ & E05B & $\begin{array}{l}\text { Security systems for windows and doors (locks; keys; } \\
\text { window or door fittings; safes) }\end{array}$ \\
\hline B61B & Railway systems; equipment & G000 & Physics \\
\hline B61D & Body details or kinds of railway vehicles & G01B & $\begin{array}{l}\text { Measuring arrangements characterized by the use of electric } \\
\text { or magnetic means }\end{array}$ \\
\hline B61F & $\begin{array}{l}\text { Rail vehicle suspensions, e.g., underframes, bogies or } \\
\text { arrangements of wheel axles }\end{array}$ & G01D & $\begin{array}{l}\text { Component parts of measuring arrangements (not specially } \\
\text { adapted for a specific variable) }\end{array}$ \\
\hline B61H & Brakes or other retarding apparatus particular to rail vehicles & G01M & Testing of static or dynamic balance of machines or structures \\
\hline B61J & Shifting or shunting of rail vehicles & G01P & $\begin{array}{l}\text { Measuring linear or angular speed, acceleration, deceleration } \\
\text { or shock; indicating presence or absence of movement; } \\
\text { indicating direction of movement }\end{array}$ \\
\hline B61K & Other auxiliary equipment for railways & G01R & $\begin{array}{l}\text { Measuring of electric variables; measuring of magnetic } \\
\text { variables }\end{array}$ \\
\hline B61L & Guiding railway traffic; ensuring the safety of railway traffic & G01S & Radio direction-finding \\
\hline B62D & Motor vehicles; trailers & G08B & Signaling or calling systems; order telegraphs; alarm systems \\
\hline B $62 \mathrm{~K}$ & Cycle axle suspensions & & \\
\hline B64D & $\begin{array}{l}\text { Equipment for fitting in or to aircraft; flying suits; parachutes; } \\
\text { arrangements or mounting of power plants or propulsion } \\
\text { transmissions in aircraft }\end{array}$ & & \\
\hline B64F & Ground or aircraft-carrier-deck installations & & \\
\hline B65G & Transport or storage devices & & \\
\hline
\end{tabular}


Fig. 4 Global distribution of patents from the top five patentcontributing countries. Data Source: Innography patent database (extracted on November 26, 2017)

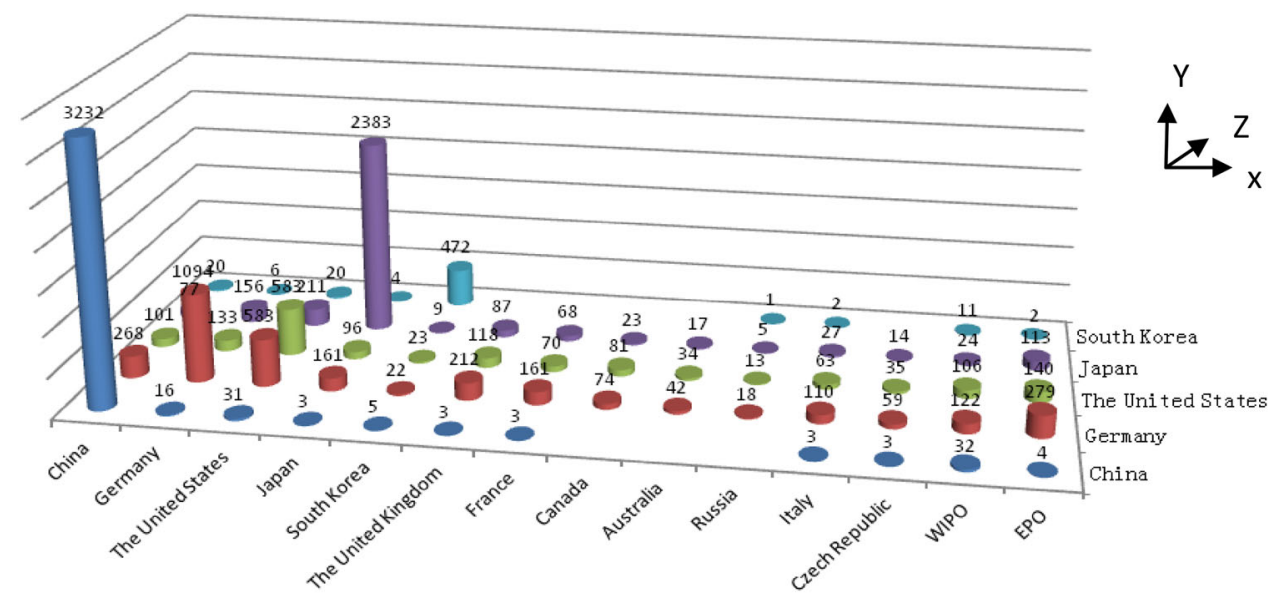

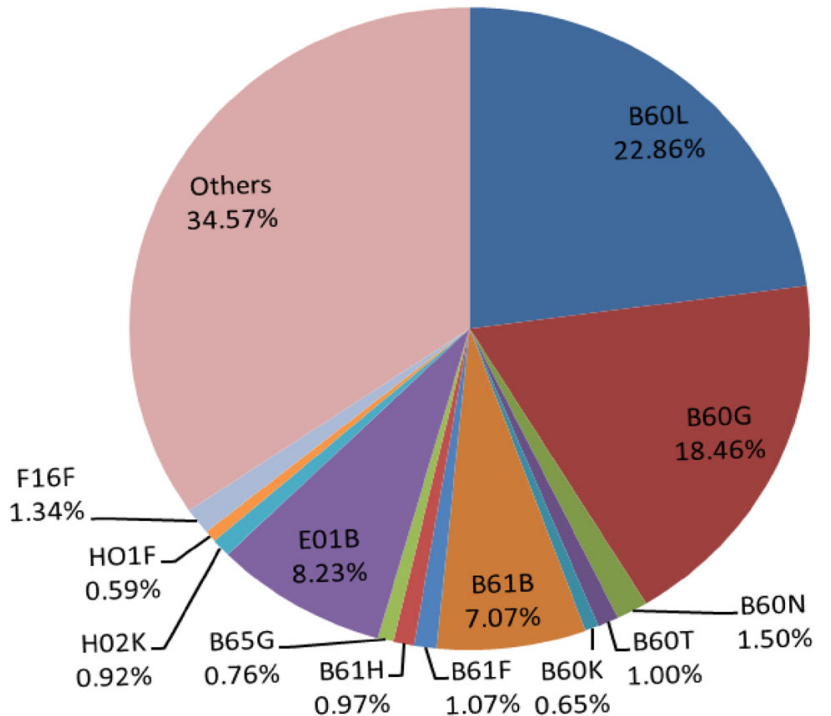

Fig. 5 Distribution of maglev-related patents by IPC classification. Data Source: Innography patent database (extracted on November 26, 2017)

for technologies related to maglev transportation systems. However, the countries appear to have differentiated concentrations. Table 3 shows that China is more concerned with the stability of the technologies and considers vehicle suspension systems and bogies $(\mathrm{B} 61 \mathrm{~F})$ a main research focus. Germany pays more attention to driving safety, and its main research and development focus is brakes and retarding apparatuses for rail vehicles $(\mathrm{B} 61 \mathrm{H})$. The USA focuses on passenger experience and on improving the comfort of passenger facilities $(\mathrm{B} 60 \mathrm{~N})$ as well as the effectiveness of shock reduction and absorption (F16F). Japan and South Korea concentrate on energy saving and efficiency, including environmental protection, with a research focus on magnets, inductance, transformers, and the selection of materials for their magnetic properties
Table 3 Comparison of the top five research perspectives of the top five patent-contributing countries and the world

\begin{tabular}{lllllll}
\hline Rank & Overall & China & Germany & USA & Japan & South Korea \\
\hline 1 & B60L & B60L & B60L & B60L & B60G & B60L \\
2 & B60G & B60G & B60G & B60G & B60L & B60G \\
3 & E01B & E01B & E01B & B61B & B61B & E01B \\
4 & B61B & B61B & B61B & B60N & E01B & B61B \\
5 & F16F & B61F & B61H & F16F & H01F & B65G \\
\hline
\end{tabular}

Please refer to Table 1 for the technology descriptions of the codes

$(\mathrm{H} 01 \mathrm{~F})$, as well as transportation and storage devices (B65G).

\subsection{Research Status of Innovative Organizations of Maglev Technology}

\subsubsection{Major Innovative Organizations and Types}

Next, we analyze the patentees in the collected samples. Since the English names of some Chinese patentees are not consistent in the collected samples, we referred to the English names used in the patent library of the State Intellectual Property Office of China (SIPO). The top 20 innovative organizations with the most maglev technology patents were then extracted (see Fig. 6).

Among the 20 innovative organizations, eight are from Japan, six are from China, four are from Germany, and the remaining two are from the USA and South Korea. The number of innovative organizations in China is the second highest, exceeded only by that in Japan, which suggests that China has focused intensely on the research and development of technologies related to maglev transportation systems. However, five of the six Chinese patentees are from universities and research institutes; only Beijing Maglev is a private firm. By contrast, the most 
Fig. 6 Top 20 innovative organizations with the most maglev-related patents. Data Source: Innography patent database (extracted on November 26, 2017)

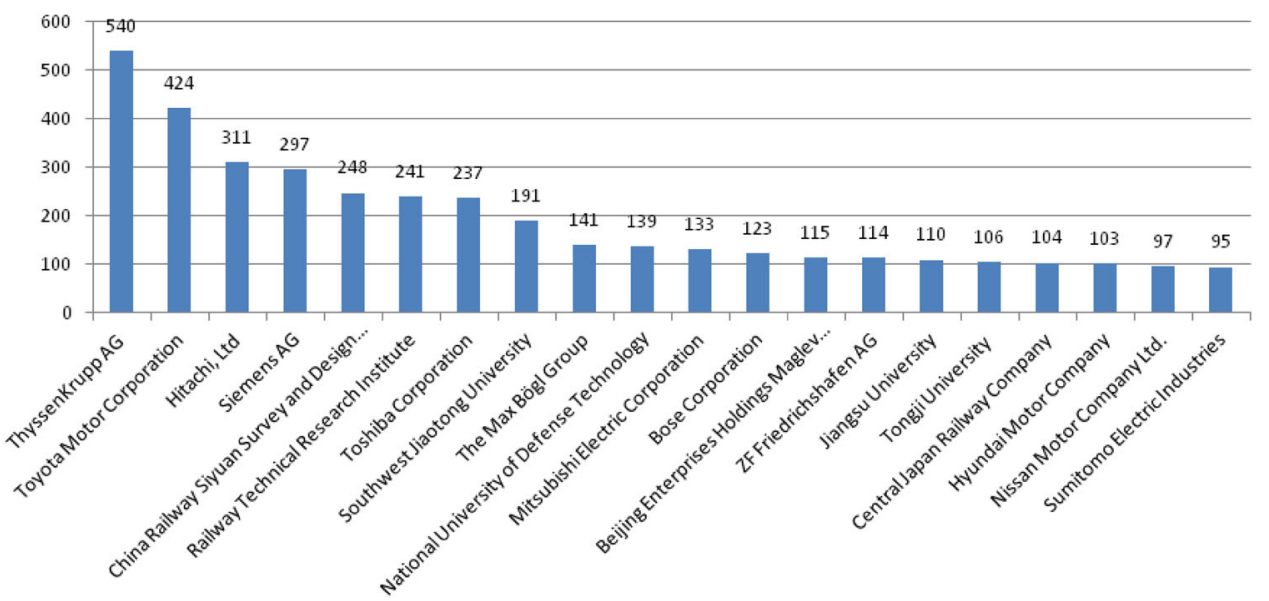

innovative organizations in other countries are all enterprises. All four innovative organizations in Germany, all the innovative organizations in the USA and South Korea, and seven of the eight innovative organizations in Japan are enterprises. An analysis of the innovative organizations' types shows that the industrialization of the maglev transportation system in China is lagging that in developed countries.

\subsubsection{Patent Distribution among Major Innovative Organizations}

A further analysis of the patent distribution among the major innovative organizations reveals the patentees' future technology development directions as well as their competitive strategies. In Fig. 7, the $X$-axis represents the top 20 innovative organizations, the $Z$-axis represents the countries and regions where the patents are registered, and the $Y$-axis represents the number of patents registered.

For brevity's sake, this descriptive analysis considers only the most representative institutions with the most patents. The global distribution of patents among the top five major innovative maglev organizations is shown in Table 4.

Table 4 shows that ThyssenKrupp AG in Germany owns the most patents related to maglev transportation systems. Its patented technologies are registered in 17 countries and regions, and most are registered in Germany (31.3\%), the USA (17.96\%), China (17.78\%), at the EPO $(16.11 \%)$, and at the WIPO $(9.07 \%)$. Toyota Motor Corporation in Japan registered patents related to maglev transportation technology in 10 countries and regions, including Japan $(68.87 \%)$, Germany $(8.49 \%)$, the USA $(8.25 \%)$, the EPO $(8.02 \%)$, and China (7.08\%). The China Railway Siyuan Survey and Design Group Co., Ltd. (China) registered most of its patents related to maglev transportation technology in China $(96.37 \%)$ and at the EPO $(3.63 \%)$. The patented technologies of the Bose Corporation of the USA are registered in eight countries and regions, including the USA (30.89\%), the EPO (22.76\%), Germany (21.14\%), China (17.07\%), and Japan (14.63\%). The patented technologies of the Hyundai Motor Company of South Korea are registered in four countries and regions, including South Korea (83.5\%), China (9.71\%), the USA (3.88\%), and Germany $(2.91 \%)$.

These data show that the innovative organizations in Germany (represented by ThyssenKrupp AG), the USA (represented by Bose Corporation), and Japan (represented by Toyota Motor Corporation) have a relatively balanced geographical distribution of patents, indicating that they have used a "carpet" distribution pattern and patent-fencing strategy [20]. As a result, they have formed a global network of patents and created a clear advantage in the development of the technology as well as in market competition. However, innovative organizations in China (represented by China Railway Siyuan Survey and Design Group Co., Ltd.) and South Korea (represented by Hyundai Motor Company) have mainly targeted their domestic markets, leading to a noticeable disadvantage in terms of international technological development and market competition.

\subsubsection{Research Focus Distribution Among Major Innovative Organizations}

Figure 8 shows the research focus distribution of the top 20 major innovative organizations. The figure shows that the research focus of these organizations mainly covers technologies related to electric propulsion for vehicles (B60L), vehicle suspension control (B60G), railway systems and equipment (B61B), and railway construction (E01B).

Detailed data on the patented technology classification of the top 20 innovative maglev organizations are provided in Table 5. 
Fig. 7 Distribution of patents among the top 20 major innovative organizations. Data Source: Innography patent database (extracted on November 26, 2017)

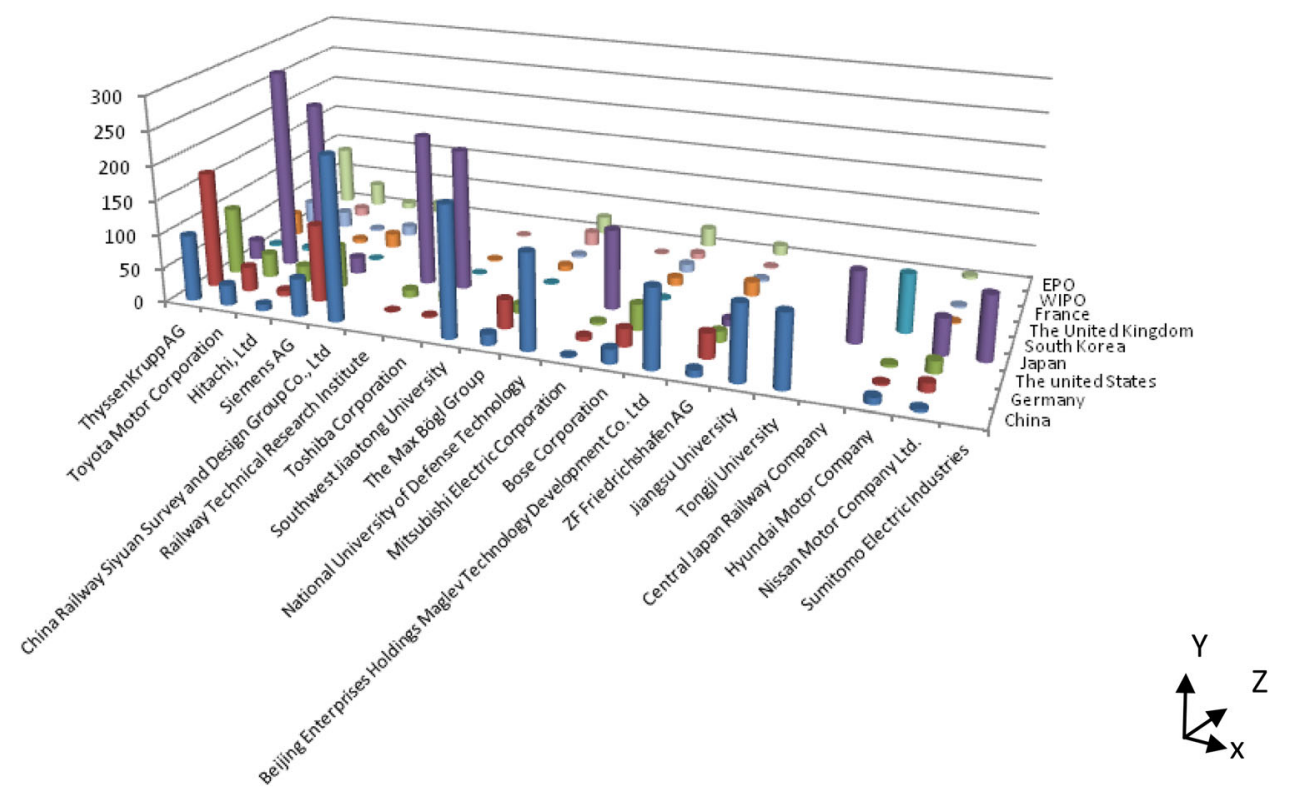

Table 4 Global patent distribution among the top 5 major innovative maglev organizations

\begin{tabular}{|c|c|c|c|c|c|}
\hline $\begin{array}{l}\text { Organization global } \\
\text { distribution }\end{array}$ & $\begin{array}{l}\text { ThyssenKrupp } \\
\text { AG }\end{array}$ & $\begin{array}{l}\text { Toyota Motor } \\
\text { Corporation }\end{array}$ & $\begin{array}{l}\text { China Railway Siyuan Survey and Design } \\
\text { Group Co., Ltd }\end{array}$ & $\begin{array}{l}\text { Bose } \\
\text { Corporation }\end{array}$ & $\begin{array}{l}\text { Hyundai Motor } \\
\text { Company }\end{array}$ \\
\hline China & $96(17.78 \%)$ & $30(7.08 \%)$ & $239(96.37 \%)$ & $21(17.07 \%)$ & $10(9.71 \%)$ \\
\hline Germany & $169(31.3 \%)$ & $36(8.49 \%)$ & & $26(21.14 \%)$ & $3(2.91 \%)$ \\
\hline USA & $97(17.96 \%)$ & $35(8.25 \%)$ & & $38(30.89 \%)$ & $4(3.88 \%)$ \\
\hline Japan & $29(5.37 \%)$ & $292(68.87 \%)$ & & $18(14.63 \%)$ & \\
\hline South Korea & $3(0.56 \%)$ & $5(1.18 \%)$ & & $2(1.63 \%)$ & $86(83.5 \%)$ \\
\hline UK & $33(6.11 \%)$ & 22() $5.19 \%$ & & $12(9.76 \%)$ & \\
\hline France & $33(6.11 \%)$ & $24(5.66 \%)$ & & $12(9.76 \%)$ & \\
\hline Canada & $27(5 \%)$ & & & & \\
\hline Australia & $12(2.22 \%)$ & $2(0.47 \%)$ & & & \\
\hline Russia & $6(1.11 \%)$ & $4(0.94 \%)$ & & & \\
\hline Italy & $27(5 \%)$ & $7(1.65 \%)$ & & $7(5.69 \%)$ & \\
\hline Czech Republic & $22(4.07 \%)$ & $7(1.65 \%)$ & & & \\
\hline WIPO & $49(9.07 \%)$ & $12(2.83 \%)$ & $9(3.63 \%)$ & $8(6.5 \%)$ & \\
\hline EPO & $87(16.11 \%)$ & $34(8.02 \%)$ & & $28(22.76 \%)$ & \\
\hline
\end{tabular}

The table shows that most of the patents $(84.64 \%)$ of ThyssenKrupp AG are in the classifications of B60L (electric propulsion for monorail vehicles, suspension vehicles or rack railways, magnetic suspension or levitation for vehicles; 41.67\%), E01B (permanent way; permanentway tools; machines for making railways of all kinds; $27.04 \%)$, and B61B (15.93\%). Most of the patents $(62.05 \%)$ of Hitachi, Ltd are in B60L, B60G, and B61B, accounting for $31.51,19.94$, and $10.6 \%$ respectively. Most of the patents $(64.66 \%)$ of Mitsubishi Electric Corporation are in B60L (33.83\%), B61B (16.54\%), and E01B $(14.29 \%)$. More than two-thirds of the patents $(67.82 \%)$ of
Beijing Maglev are in B60L (30.43\%), G01P (20\%), and B60M $(17.39 \%)$. Most of the patents $(59.69 \%)$ of Southwest Jiaotong University are in B60L (46.6\%), B61B $(6.81 \%)$, and B61F $(6.28 \%)$. Most of the patents $(58.99 \%)$ of the National University of Defense Technology are in $\mathrm{B} 60 \mathrm{~L}, \mathrm{~B} 61 \mathrm{~F}$, and $\mathrm{B} 61 \mathrm{~L}$, accounting for 41.73, 10.07, and $7.19 \%$ of its patents, respectively. Most of the patents $(63.2 \%)$ of Tongji University are in B60L, E01B, and B61D, accounting for $36.79,15.09$, and $11.32 \%$ of its patents, respectively. Most of the patents $(62.65 \%)$ of the Railway Technical Research Institute are in B60L (47.3\%) and B61B (15.35\%). More than four-fifths of the patents 
Fig. 8 Distribution of research focus of the top 20 innovative organizations. Data Source: Innography patent database (extracted on November 26, 2017)

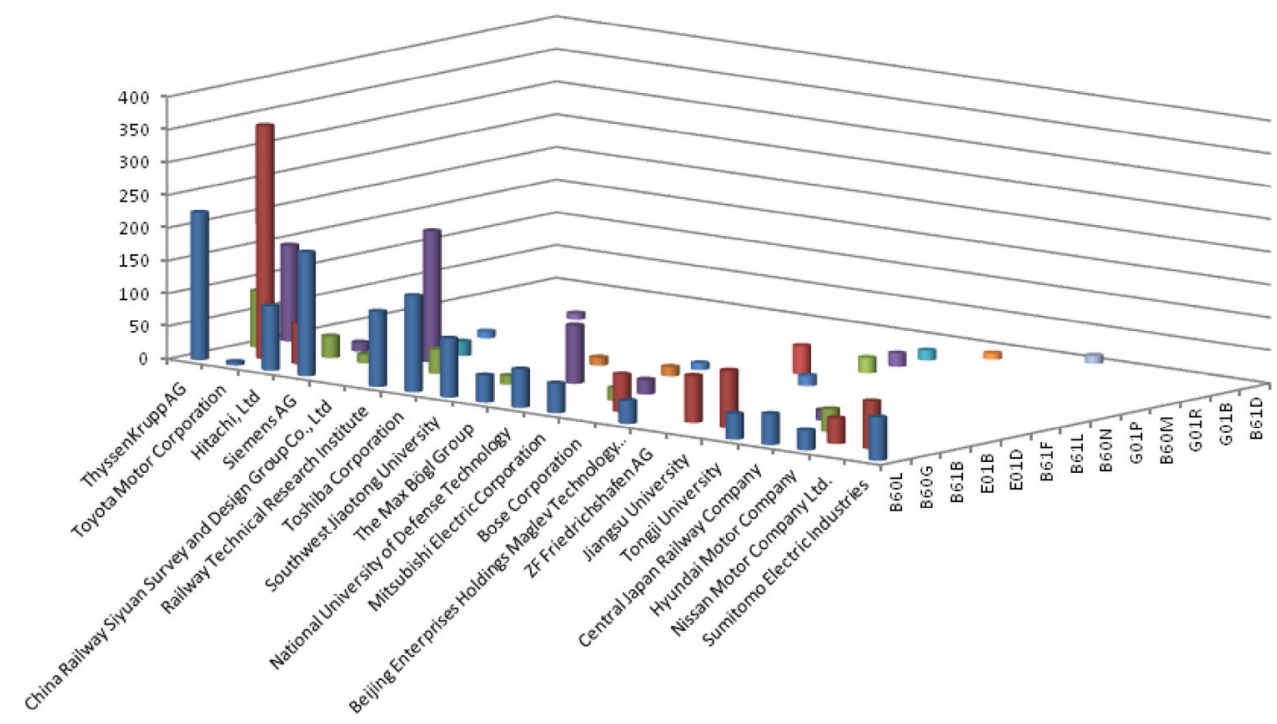

Table 5 Top 8 innovative maglev technology organizations and their patent distribution focuses

\begin{tabular}{|c|c|c|c|c|}
\hline Organization name & $\begin{array}{l}\text { Majority patents } \\
\text { registered area }\end{array}$ & $\begin{array}{l}\text { 2nd majority patents } \\
\text { registered area }\end{array}$ & $\begin{array}{l}\text { 3rd majority patents } \\
\text { registered area }\end{array}$ & $\begin{array}{l}\text { Total } \\
(\%)\end{array}$ \\
\hline ThyssenKrupp AG & B60L $(41.67 \%)$ & E01B $(27.04 \%)$ & B61B $(15.93 \%)$ & 84.64 \\
\hline Hitachi, Ltd & B60L $(31.51 \%)$ & B60G (19.94\%) & B61B $(10.6 \%)$ & 62.05 \\
\hline Mitsubishi Electric Corporation & B60L $(33.83 \%)$ & B61B $(16.54 \%)$ & E01B $(14.29 \%)$ & 64.66 \\
\hline Beijing Maglev & B60L $(30.43 \%)$ & G01P $(20 \%)$ & B60M (17.39\%) & 67.82 \\
\hline Southwest Jiaotong University & B60L (46.6\%) & $\mathrm{B} 61 \mathrm{~B}(6.81 \%)$ & $\mathrm{B} 61 \mathrm{~F}(6.28 \%)$ & 59.69 \\
\hline National University of Defense Technology & B60L $(41.73 \%)$ & B61F $(10.07 \%)$ & B61L (7.19\%) & 58.99 \\
\hline Tongji University & B60L $(63.2 \%)$ & E01B $(15.09 \%)$ & B61D $(11.32 \%)$ & 63.2 \\
\hline Railway Technical Research Institute & B60L (47.3\%) & B61B $(15.35 \%)$ & H01F $(9.54 \%)$ & 72.19 \\
\hline Bose Corporation & B60G $(46.34 \%)$ & B60N $(34.96 \%)$ & $\mathrm{F} 16 \mathrm{~F}(8.13 \%)$ & 89.43 \\
\hline Central Japan Railway Company & B60L $(45.19 \%)$ & B61B $(33.65 \%)$ & $\mathrm{H} 01 \mathrm{~F}(4.81 \%)$ & 83.65 \\
\hline Hyundai Motor Company & B60G $(37.86 \%)$ & B60L $(29.13 \%)$ & $\mathrm{F} 16 \mathrm{~F}(5.83 \%)$ & 72.82 \\
\hline Toyota Motor Corporation & B60G $(83.96 \%)$ & F16F $(3.77 \%)$ & B60K $(2.12 \%)$ & 89.85 \\
\hline Jiangsu University & B60G $(79.09 \%)$ & $\mathrm{F} 16 \mathrm{~F}(5.45 \%)$ & B60K $(4.55 \%)$ & 89.09 \\
\hline Nissan Motor Company Ltd. & B60G $(75.26 \%)$ & B60K (6.19\%) & B60R $(4.12 \%)$ & 85.57 \\
\hline ZF Friedrichshafen AG & B60G $(62.28 \%)$ & G01B $(7.89 \%)$ & B62D $(6.14 \%)$ & 76.29 \\
\hline Sumitomo Electric Industries & B60L $(69.47 \%)$ & E01B $(7.38 \%)$ & B61B $(7.37 \%)$ & 84.22 \\
\hline Siemens AG & B60L $(63.3 \%)$ & B61B $(4.38 \%)$ & B61L $(3.37 \%)$ & 71.05 \\
\hline Toshiba Corporation & B60L (61.6\%) & B61B $(9.7 \%)$ & E01B $(6.75 \%)$ & 78.05 \\
\hline $\begin{array}{l}\text { China Railway Siyuan Survey and Design } \\
\text { Group Co., Ltd }\end{array}$ & E01B $(80.65 \%)$ & E01D $(8.87 \%)$ & B60M $(2.02 \%)$ & 91.54 \\
\hline Max Bögl Group & E01B $(62.41 \%)$ & B60L $(29.08 \%)$ & B61B (4.96\%) & 96.45 \\
\hline
\end{tabular}

Please refer to Table 1 for technology descriptions of the codes

(81.3\%) of Bose Corporation are in B60G and B60N, accounting for $46.34 \%$ and $34.96 \%$ of its patents, respectively. More than three-quarters of the patents $(78.84 \%)$ of the Central Japan Railway Company are in B60L (45.19\%) and B61B (33.65\%), and approximately two-thirds of the patents $(66.99 \%)$ of the Hyundai Motor Company are in
B60G (37.86\%) and B60L (29.13\%). These findings show that these innovative organizations are able to fully utilize their resource endowments to seek breakthroughs in the chain of maglev technologies and ultimately expand the comprehensive value chain through a concentric diversification strategy. 
The patents of Toyota Motor Corporation, Jiangsu University, Nissan Motor Company Ltd., and ZF Friedrichshafen AG are concentrated in B60G, accounting for $83.96,79.09,75.26$, and $62.28 \%$ of their maglev technology-related patents, respectively. The patents of Sumitomo Electric Industries, Siemens AG, and Toshiba Corporation are mainly in B60L, accounting for $69.47,63.3$, and $61.6 \%$ of their maglev technology-related patents, respectively. The patents of China Railway Siyuan Survey and Design Group Co., Ltd. and the Max Bögl Group are concentrated in E01B, accounting for $80.65 \%$ and $62.41 \%$ of their maglev technology-related patents, respectively.

The data in Table 5 suggest that the top 20 innovative organizations generally focus their resources on a single technology area in order to become global technological leaders through a specialization strategy.

\subsection{Identifying Core Patents Related to Maglev Technology}

\subsubsection{Patent Strength}

Core patents are the patents needed to manufacture a given product; they generally cannot be bypassed [21]. The Innography platform contains a powerful core patent mining capability. Using the results of research on patent value determination conducted by the University of California, Berkeley, George Mason University, Stanford University, and the University of Texas, Innography divides the strength of patents into three levels: A patent with a strength indicator value equal to or greater than $80 \%$ is considered a core patent; a patent with an indicator between 30 and $80 \%$ is considered an important patent; and a patent with an indicator less than $30 \%$ is considered a general patent [22].

An analysis of patent strength shows that 229 of the investigated patents are core patents (1.87\%), 2557 are important patents $(20.84 \%)$, and 9483 are general patents (77.29\%). The relative scarcity of core patents highlights their value in the field of technology.

\subsubsection{Core Patents}

An in-depth analysis of the 229 core patents provides highvalue scientific and technological intelligence about the field and reveals the research directions and trends in maglev technology.

Concerning the origins of core patent holders, approximately half $(114,49.78 \%)$ are from the USA, accounting for $8.69 \%$ of the nation's total patents. More than one-fifth $(52,22.71 \%)$ of the core patents are held by German organizations, accounting for $2.07 \%$ of the country's total patents. Japan has 27 (11.79\%) core patents, accounting for
$0.89 \%$ of its total patents. Only three of the core patents $(1.31 \%)$ are from China, much less than for the UK and South Korea. Core patents accounted for only $0.09 \%$ of China's patents. Thus, although Chinese organizations have the highest number of patent applications, few of these patents are core patents, indicating that the quality of the patents held by China is generally not high.

The classification of core patents is presented in Table 6. Most of the core patents belong to the following five main classifications: performing operations (B000, $181 ; 78.7 \%$ ), which includes vehicle suspension arrangements, electric propulsion for vehicles, railway systems and equipment; electricity (H000, 15; 6.5\%); mechanical engineering (F000, 14; 6.1\%); fixed construction (E000, $12 ; 5.2 \%)$; and physics (G000, 8; 3.4\%). Thus, the core technologies of maglev transportation systems are concentrated in the domains of suspension control, propulsion technology, and railway systems.

The main contributors of core patents-the USA, Germany, and Japan-have core patents distributed across all five classifications. However, China has only three core patents in B000, including two patents related to vehicle suspension arrangements (B60G) and one patent related to railway systems and equipment (B61B).

\section{Conclusions and Suggestions}

\subsection{Conclusions}

This study explored and analyzed the global development trend in maglev technology, the distribution of patentcontributing countries, their associated research focuses, and their core patents. The following conclusions can be drawn.

(1) The total number of patent applications related to maglev technology continues to grow. After a long period of scientific discovery and technological innovation, as well as a difficult stage of engineering demonstration and implementation, the maglev transportation system, as a new rail transit mode, has entered the industrialization stage, characterized by standardized technologies, a scaled market size, and popularized consumption.

(2) China, Japan, Germany, the USA, and South Korea have contributed $87.3 \%$ of the world's patented maglev technologies. The maglev technologies in Western countries are the most mature, and the patents of Western organizations have been registered in 20-30 countries and regions.

(3) Most of the patents are related to the electric propulsion of vehicles, vehicle suspension control, 
Table 6 IPC classifications of the core patents

\begin{tabular}{lcllll}
\hline IPC code & Core patent (number) & IPC code & Core patent (number) & IPC code & Core patent (number) \\
\hline B000 & 181 & B61L & 2 & F16M & 2 \\
B60G & 67 & B61J & 1 & F16K & 1 \\
B60L & 55 & B61K & 1 & F16H & 1 \\
B60T & 7 & B61H & 1 & E000 & 12 \\
B60K & 6 & B62D & 2 & E01B & 8 \\
B60N & 5 & B62K & 1 & E01F & 1 \\
B60R & 4 & B64F & 1 & E01C & 1 \\
B60Q & 3 & B64D & 1 & E05B & 2 \\
B60C & 2 & H000 & 15 & G000 & \\
B60B & 2 & H02K & 8 & G01M & 2 \\
B60D & 2 & H02J & 2 & G01P & 2 \\
B60P & 2 & H02P & 2 & G01D & 1 \\
B60W & 1 & H02N & 1 & G01B & 1 \\
B60S & 1 & H01F & 2 & G01S & 1 \\
B60H & 1 & F000 & 14 & G08B & 1 \\
B60J & 1 & F16F & 7 & & \\
B61B & 12 & F16D & 3 & & \\
\hline
\end{tabular}

Please refer to Table 1 for the technology descriptions of the codes and railway system and construction tools. These represent the core technologies and research focuses in the development of maglev transportation systems.

(4) China is second only to Japan in the number of productive innovative organizations. However, most of the innovative organizations in developed countries are private firms, while most of the innovative organizations in China are universities and research institutions. This indicates that the industrialization of maglev technology in China is lagging that in the other main patent-contributing countries.

(5) An in-depth analysis of the core patents reveals that developed countries have a higher ratio of core patents to total patents. In addition to reaching commanding heights of technology, developed countries have also achieved a more sophisticated distribution of patented technologies from the perspectives of both geography and the industrial chain.

\subsection{Suggestions}

Based on the research results about the global competition in maglev technology, the following suggestions and recommendations are proposed from both a national/governmental (macro) and organizational (micro) level.

(1) It is necessary to strengthen technological foresight and forecasting capabilities and focus more on breakthroughs in core technologies and improving patent quality for both national governments and innovative organizations. Accordingly, technological foresight should be developed at both the national and industrial levels to identify priority areas for technological development through the overall screening of maglev transportation systems. The identified areas should be then included in national science and technology programs to fill the research gaps in this area. In addition, technological forecasting should be conducted at the enterprise level to identify the technological frontier and trends as well as research focuses and gaps, thereby gaining a mastery of the core technologies and enhancing patent quality.

(2) It is important to train and nurture leading technological talents, strengthen university-industry cooperation, and promote enterprise-oriented industry technological alliances. On the national level, maglev technology should be considered a "first class" initiative, and more high-quality scientific researchers in the field must be trained. In addition, governments should conduct extensive searches for technological elites around the world. At the organizational level, enterprise-oriented university-industry cooperation among enterprises, universities, and research institutions should be established so that they may compensate one another's shortcomings, share benefits and risks, and jointly develop core technologies, thereby breaking through the 
development bottlenecks in maglev transportation systems.

(3) It is important to set up various international cooperatives and exchanges, introduce patented technologies, and re-innovate new technologies. Governments, enterprises, and research institutions should create conditions for international exchange and cooperation with countries that have advanced maglev technologies and introduce patented technologies through patent transfer, licensing, and cross-licensing. The aim is to master core technologies through reverse engineering and development, break through the technological bottlenecks, and gradually form a global network of registered patents in order to establish a competitive advantage in the global market.

Acknowledgements The paper is part of the National Natural Science Foundation Project (No. 71562022) and part of Jiangxi Natural Science Foundation Project (No. 20171BAA208014).

Open Access This article is distributed under the terms of the Creative Commons Attribution 4.0 International License (http://crea tivecommons.org/licenses/by/4.0/), which permits unrestricted use, distribution, and reproduction in any medium, provided you give appropriate credit to the original author(s) and the source, provide a link to the Creative Commons license, and indicate if changes were made.

\section{References}

1. Brown JL (2003) High-speed rail: maglev technology comes of age in Shanghai. Civ Eng ASCE 73(2):14-15

2. Yan LG, Sun GS, Fang JR, Yu MG (2002) High-speed MAGLEV in China. In: 7th International conference on applications of advanced technologies in transportation (AATT), pp 321-328

3. Najafi FT, Nassar FE (1996) Comparison of high-speed rail and maglev systems. J Transp Eng 122(4):276-281

4. Nakagawa A, Matsuda S (2005) Status of development and running tests on Japan's superconducting maglev. Transp Res Rec Railr Intercity Rail Passeng Track Des Maint Other Top 1916:26-29
5. Park DY, Shin BC, Han H (2009) Korea's urban maglev program. Proc IEEE 97:1886-1891

6. Wikipedia (2017) Changsha maglev express. https://en.wikipedia. org/wiki/Changsha_Maglev_Express. Accessed 21 Sept 2017

7. Dan HJ (2016) Discussion of bridge construction road work traffic organization design at Beijing urban rail transit line maglev S1 valley across longlin road. Sci Mosaic 5:134-137

8. Lu-guang YAN (2005) Suggestion for actively developing maglev transportation in China. Adv Technol Electr Eng Energy 24(1):1-7

9. Hellinger R, Mnich P (2009) Linear motor-powered transportation: history, present status, and future outlook. Proc IEEE 97:1892-1900

10. Vuchic VR, Casello JM (2002) An evaluation of maglev technology and its comparison with high speed rail. Transp Q 56(2):33

11. Thornton RD (2009) Efficient and affordable maglev opportunities in the United States. Proc IEEE 97:1901-1921

12. Chan L, Aldhaban F (2009) Technology transfer to China: with case studies in the high-speed rail industry. In: PICMET 2009 proceedings, Portland, pp 2858-2867

13. Minakami M (2004) Study on moving maglev highway systems. Mov Through Millenn Autom People Mov VIII:1-12

14. Barber JB (1986) Maglev: the urban market. In: International conference on maglev and linear drives (cat. no. 86CH2276-4), 14-16 May 1986. Vancouver, BC, pp 13-20

15. Fa L, Zhang YH, Yang J (2014) The application of Innography patent for indexing and analysis. Ind Sci Trib 14:43-45

16. Zhang S, Zhang F, Xu HQ, Dai EM, Zhou DD (2013) Knowledge mining, competitive warning and strategic layout of core patents based on innography. Libr Inf Serv 19:127-133

17. Wan CS, Zeng GP (2005) Quadruplicitism" and philosophy of industry. Stud Dialectics Nat 10:43-46

18. Gou JS, Li JY, Ruan PN (2014) The strategy research for overcoming barriers in emerging industries. Reform Econ Syst 5:92-96

19. Wang XB (2003) Dynamic trend of new technique development in Shanghai based on international patents analysis. Sci Technol Manag Res 4:98-100

20. Liu QY, Dongfang C (2013) Advanced technology value creation and its industrialization operation and practice. Shanhai Jiaotong University Express, Shanghai, pp 183-192

21. Huo CT (2012) Methods for judging enterprise core patent. Information 11:95-99

22. Lu P, Ke LX (2012) Core patents excavation by using Innography. Libr Work Study 8:122-125 